\title{
Relationship between agrarian contracts and renewable energy production in sugarcane agroindustry
}

\author{
Patrícia J. de Almeida ${ }^{1 *}$, Carlos T. Salinas ${ }^{1,2}$, Lucas Ramos $^{1}$, and Daniel Marceço-Aldana ${ }^{1}$ \\ ${ }^{1}$ University of Piura, Ramón Mugica 131, Av., Urb. San Eduardo, Piura, Peru \\ ${ }^{2}$ Santa Cecilia University, Postgraduate Program of Mechanical Engineering, Rua Cesário Mota 08, Sala F-34, Santos, Brazil
}

\begin{abstract}
Many agroindustries that process sugarcane raw to produce sugar and ethanol, and for energy cogeneration have difficulties to obtain all the necessary raw material. The agrarian contract practice can allow access to land in order to increase the production of sugarcane, without immobilizing resources in terms of the purchase of land, reducing the idle capacity of industrial plant, and increasing the cogeneration of energy by burning bagasse and sugarcane straw. It appears that the form of production of sugarcane (i.e., through land leasing, sharecropping, independent producers, etc.) can significantly affect the total costs of the industrial process. This work looks to find an empirical relation between the type of sugarcane producers and the energy produced by the mill based on data of the Agricultural Census of Brazil and monitoring data of power plant operation parameters of a typical mill in Brazil. It was found that the sugarcane raw coming from lands worked for tenants and sharecroppers increased his participation $112 \%$ and $469 \%$ respectively in the energy generation in the period 2006 to 2017.
\end{abstract}

\section{Introduction}

The utilization of clean sources and renewable energy, the increase in sugar consumption, and the development of other bioproducts (e.g., fuels, plastic products) by the sugar-energy sector has increased the demand for sugarcane [1, 2]. Studies show that there is a high potential for energy generation from the burning of sugarcane biomass residues (i.e., bagasse and straw) in Brazil $[3,4]$. However, many agricultural industries that burn sugarcane biomass face difficulties when it comes to obtaining the main raw material they need.

In Brazil, sometimes, land access has been an obstacle for sugarcane producers. There are reports in the literature on the practice of entering into agrarian contracts (i.e., leasing and sharecropping) by sugarcane agribusinesses in Brazil, as a way of expanding sugarcane production [1, 5, 6, 7]. In Brazil, for many landowners, the practice of agrarian contracts as leasing and sharecropping for sugarcane production to supply sugarcane industry may be more profitable than if they worked the land themselves [1, 8]. For tenants, sharecroppers and for independent sugarcane producers generally the contracts signed with the mills, although they may have restrictive clauses, provide security in terms of product supply and payment. From the mill's point of view, the agrarian contracts have led to an increase in the raw material production needed to generate energy from sugarcane solid residues as bagasse and sugarcane straw [5].

The objective of this article is to analyse the forms of access to land (for example, leasing and/or sharecropping) and their relationship with the expanding of the production of raw materials for the sugarcane agroindustry in Brazil. Furthermore, it is analysed if the practice of agrarian contracts influences in the increase of energy production of mills by using the solid residues of sugarcane biomass.

\section{Overview of agrarian contracts in Brazil}

There is a vast literature on the topic of agrarian contract in Brazil. To sake brevity, only some relevant aspect about the practice of agrarian contracts in the sugarcane agroindustry in Brazil are presented.

In general, contracts in Brazil for the supply of sugarcane and land use contracts to produce own cane (on the part of the sugarcane agrobusinesses) have distinct forms and reflect a chronological maturity due to tax relief for both parties in the contract (i.e., agrobusinesses and sugarcane producers). In the CenterSouth Region of Brazil, as new plant installation projects were implemented in the western border areas of the State of São Paulo, in the Goiás, Mato Grosso and Mato Grosso do Sul states, agricultural sharecropping contracts began to increase gradually in order to win the trust of landowners, with price security linked to the Consecana SP (São Paulo State Sugarcane, Sugar and Ethanol Producers Council). This model is basically required in most contracts in the new sugarcane producing regions. In the sugarcane agribusiness in Brazil there is greater interest on the part of the mills in the use of the leasing or sharecropping system in

\footnotetext{
* Corresponding author: almeida_03@yahoo.com.br
} 
comparison with the production system in their own lands [9].

In the São Paulo State, most of the land occupied by the new sugarcane fields in the early 2000s was not based on purchase of land, but on tenancy/ sharecropping [10]. The production of sugarcane on land owned by the mills is only more advantageous in places very close to the industrial unit. However, in any case, the lands located around the industrial units offer enormous benefits for the mills and distilleries, since the closer to the industry is the production of raw materials, lower the transport costs, an important component in the total cost of raw sugarcane per ton [11].

The influence of land leasing contracts for the cultivation of sugarcane on the economic development of the Mato Grosso do Sul State was analyzed in [12], and a research of three alcohol and sugar producing plants, making up a total of 24 units was conducted. They noted that the location of the plant units in relation to the respective lessees was an important factor in terms of the location model adopted by the 3 plants under consideration, which made use of suppliers within a maximum radius of $42 \mathrm{~km}$. They found that greater distances imply higher production and logistic costs in terms of transport, since they were the responsibility of the tenant mills. Thus, mills prefer to buy sugarcane or lease land for cultivation always in their immediate surroundings with a view to reducing costs.

In most of the agrarian contracts, the mill is the tenant or sharecropper, and it is the agent with the greatest power when it comes to determining the contractual terms. When the producers are individuals, the tax advantage of a sharecropping is clear in relation to tenancy. Mills and distilleries, due to their relatively large infrastructure and scale of technology, generally can achieve higher productivity than can isolated producers and, therefore, can set a price per hectare which is higher than the market (if they choose to buy land), or propose a tenancy regime such that land remuneration is attractive to the owner.

The mills seek to be profitable in the industrial sector (sugar and alcohol processing). So, cultivate the raw material at levels higher than the economic optimum in the short term is required because the increase in cost can be offset by the industrial profit, since the price of the cane is determined exogenously. Therefore, the decision to buy or lease the land depends on the policy adopted by the mills and distilleries and on the existence or not of credit facilities or cash availability.

Usually, in most contracts, the plant is responsible for cultivating, maintaining, fertilizing, harvesting and transporting crops, which raises total costs. The mills prioritize contracts with up to 5 cuts (on average over 5 or 6 years) to achieve a certain degree of security for farmers or employees.

Based on this discussion, it is considered that access to land in Brazil over agrarian contracts (i.e., leasing and/or sharecropping), can contribute to increasing the production of raw materials for the sugarcane agroindustries, improving efficiency in terms of the use of productive resources in agriculture and favor the increase of the generation of renewable and clean energy.

\section{Relationship between agrarian contracts and energy generation}

To analyse the relationship between agrarian contracts and energy generation from sugarcane biomass residues in the sugarcane agroindustry in Brazil, data from the Brazilian Agricultural Census and monitoring data of energy generation in a mill at São Paulo state are used. Data from the last two editions of the Brazilian Agricultural Censuses, 2006 and 2017 censuses were used to compare the evolution of the relationship between agrarian contracts and power generation.

São Paulo State is one of the Brazilian states where the practice of agrarian contracts is more widespread [13]. The Figure 1 shows that the total number of establishments in leasehold and the total number of establishments in sharecropping increased from 2006 to 2017 in São Paulo State. It can be observed that the total area occupied by tenants grew less than the total area occupied by sharecroppers. It is important to highlight that from 2006 to 2017, both in leasehold and sharecropping, the total area of establishments corresponding to the strata of smaller area grew slightly and the total area of establishments corresponding to strata of larger area grew strongly.

According to data from the Brazilian Agricultural Census of 2017, sugarcane production in the states of the Centre-South of Brazil is an important economic activity and where the leasing of land is most profitable. A problem in the leasing market in the sugar and alcohol sector in Brazil is knowing which exploration, leasing or autonomous production system offers the greatest economic advantages for landowners and tenants.

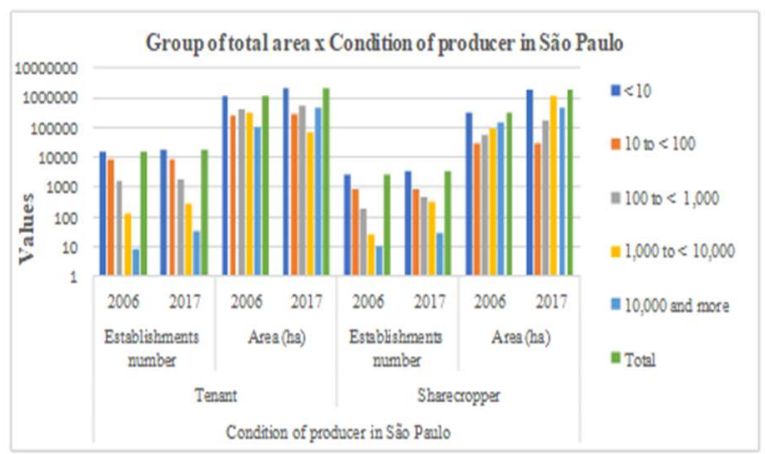

Fig. 1. Number of holdings and area, according to the producer's profile per group of total area - São Paulo (2006 and 2017).

Mills and distilleries, due to their relatively large infrastructure and scale of technology can generally achieve higher productivity than can isolated producers and, therefore, can set a price per hectare which is higher than the market (if they choose to buy land), or propose a tenancy regime such that land remuneration is attractive to the owner. In Brazil, the phenomenon that most of the land occupied by the new sugarcane mills are not based on purchase of land, but on tenancy/ sharecropping is repeated. The expansion of leased areas for the cultivation of sugarcane has changed land use in much in several states in Brazil (e.g., Parana, Sao Paulo, Minas Gerais, Goiás). This fact configures a new 
economic geography that greatly serves the interests of the sugar and alcohol sectors.

In Figure 2 is shown the comparison of total harvest area corresponding to proprietary, tenant and sharecropper from data of Brazilian Agricultural Census 2006 and 2017. It can see that the total harvested area increased from 5443082 ha to 8827550 ha. However, participation of the sharecropper and tenant in the total of harvested area increased strongly. In the other hand the participation of the proprietary condition decreased also strongly. This indicate that more and more landowners are practicing agrarian contracts in leasing or sharecropping.

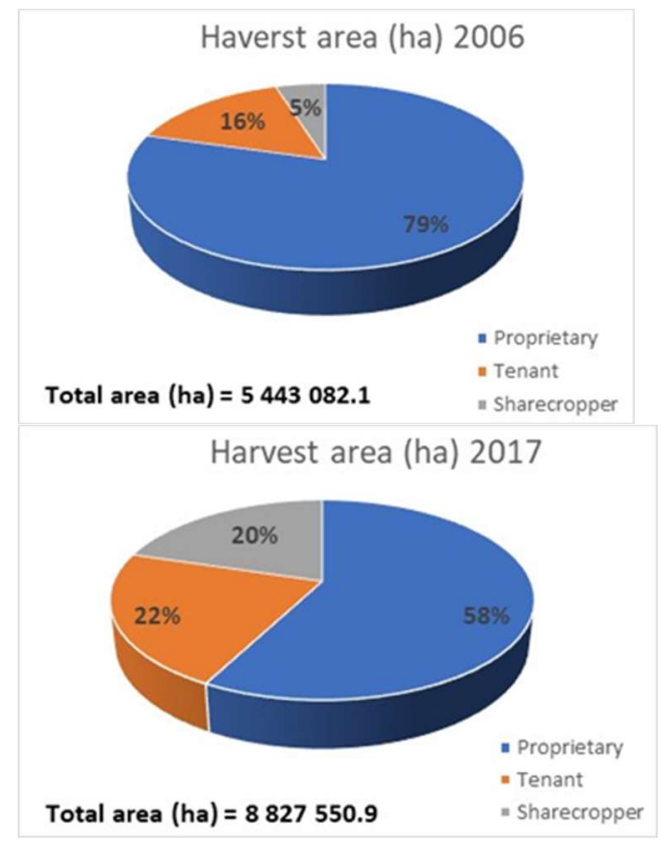

Fig. 2. Comparison of total harvest area corresponding to proprietary, tenant and sharecropper from data of Brazilian agrarian census 2006 and 2017.

To sake, a fast overview about results in a mill operation relating agrarian contract and energy generation can cite to an agroindustry organization in Goiás State [14]. It uses the cultivation of sugarcane via agricultural sharecropping contracts. It has a production capacity of 16,000 bags per day of sugar (50 kg bags) and a maximum capacity to process 13,200 tons of cane / day. In the 2009/2010 harvest, it produced $800 \mathrm{~m} 3$ / day of hydrated alcohol, $300 \mathrm{~m} 3$ / day of anhydrous alcohol and $768 \mathrm{MWh}$ per day of commercial electricity generation.

To obtain a realistic value about the relation into consumption of the raw sugarcane, the bagasse and the energy produced in a sugarcane mill, operation data in a mill at Sao Paulo State, Brazil is collected. This sugarcane mill is a typical one and produce sugar, alcohol and energy. A monitoring of the Electrical Power produced by the turbines of the power plant for 24 hours were carried out, data of consumption of sugarcane straw in the industrial process and the consumption of bagasse in the power plant of the mill were collected. The mill has a utility boiler that burn sugarcane bagasse to produce steam to supply one high pressure turbine (turbine 1, nominal power $30 \mathrm{MW}$ ) and one low pressure turbine (turbine 2, nominal power 5 MW).

In Figure 3 it is shown the monitoring data of the electrical power in MW that the turbines in the power plant of the sugarcane industry during 24 hours. Experimental data on sugarcane consumption were collected on a normal day of operation at the plant. The consumption of bagasse in the utility boiler was equal to 1908.45 tons of bagasse per day, which corresponds to 3816.9 tons of raw sugarcane per day. Based in monitoring data, on that day, turbine 1 had an average generation of $26.55 \mathrm{MWh}$ and turbine 2 had an average generation equal to $3.10 \mathrm{MWh}$. So, for an hourly energy production of $29.65 \mathrm{MWh}$ on that day and with an operation for $24 \mathrm{hr} /$ day, the mill produces 711.6 MWh per day. We can define a factor $F$ as:

\section{$\mathrm{F}=$ Energy produced/consumption of raw sugarcane (1)}

Then 711.6 MWh-day divided by $3816.9 \mathrm{t}$ cane-day, factor $\mathrm{F}$ is equal to $0.1864 \mathrm{MWh} / \mathrm{t}$ cane.

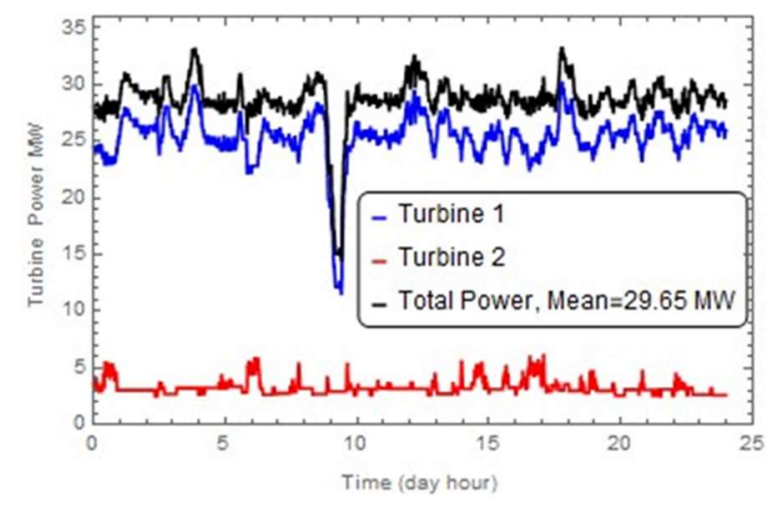

Fig. 3. Monitoring of Electrical Power Generation in a mill for 24 hours.

Based in the calculated factor $F$, the energy production related to the raw sugarcane production in the total harvest area in Brazil in 2006 and 2017 can be estimated for every condition of sugarcane producer (i.e., Proprietary, Tenant and Sharecropper). In this estimation, the operation data of this typical mill can be considered as a reasonable approximation for most of the mills in Brazil. In Figure 4 is shown the estimation of energy production in 2006 and 2017 relating the condition of the producer. It can be observed that the participation of the estimated energy production related to the raw sugarcane production for sharecropper increase from approximately $5 \%$ in 2006 to $19 \%$ in 2017. Similarly, for tenant, the participation of the estimated energy production increase from approximately $17 \%$ in 2006 to $23 \%$ in 2017 . In other hand the participation in the energy generation of the landowners or autonomous producers decrease from $78 \%$ in 2006 to $58 \%$ in 2017.

In Figure 5 is shown the variation of the harvest area and the estimated energy production. It can be observed that the total harvest area increased $62 \%$ however the estimated energy production increased $56 \%$. Among the others, the decrease of productivity of the land in term 
of $t$ cane / ha is one factor in this result. The energy production related to sharecropper condition increased more than five times in 2017 in relation to 2006. Also, the energy production related to the tenant condition increased $112 \%$ in 2017 in relation to 2006. In the case of energy production related to proprietary only had an increase of $16 \%$. It is observed that there is a relationship into the increase of tenancy and sharecropping with the increase of renewable energy production using biomass residues of raw sugarcane in the sugarcane agroindustry in Brazil.

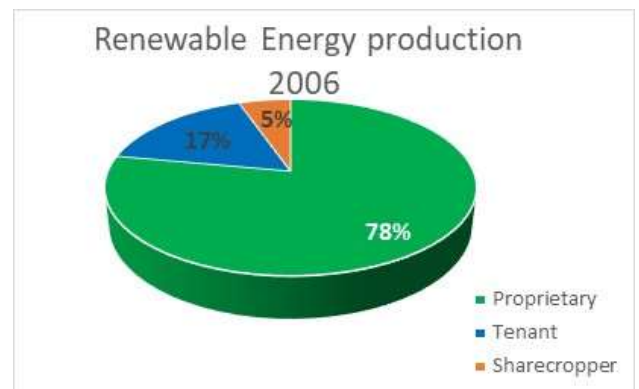

Estimated Energy (MWh) = 75190807.4

Renewable Energy Production

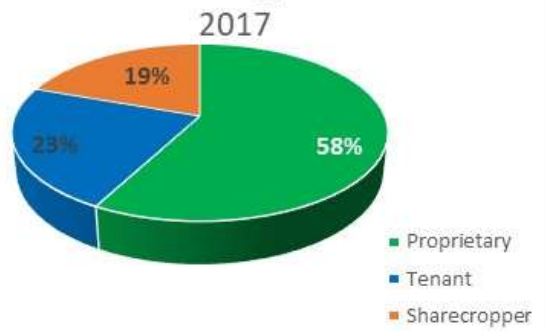

Estimated Energy (MWh) = 117609736.5

Fig. 4. Comparison of estimated renewable energy production in 2006 and 2017.

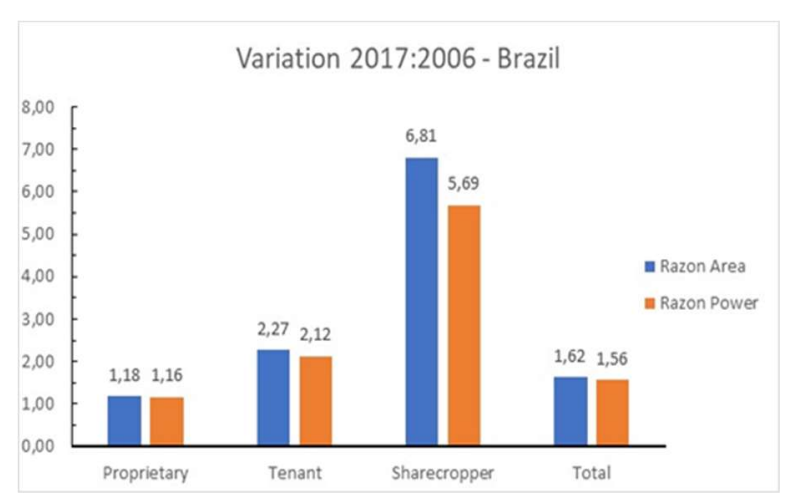

Fig. 5. Variation of Harvested Area and Renewable Energy Generation

\section{Conclusions}

In the context of the discussion with regard to the growing demand for renewable energy generation, a comparison is made with regard to different forms of access to land (leasing, sharecropping, etc.) as a mechanism to increase the production bioenergy in agroindustries in Brazil. It was found that sugarcane agroindustries in Brazil increased their access to land, via lease and / or partnership agreements. While harvested area grow $62 \%$ in the period 2006 to 2017, the tenancy and sharecropping grow were $127 \%$ and $581 \%$ respectively. Based in a monitoring data of a mill operation is estimated that renewable energy production from using biomass residues of raw sugarcane increased $56 \%$. Analysing the difference in the increasing of harvested area and energy production, the decrease of productivity of the land in term of t cane / ha is, among the others, a factor that influence in this result. Estimations indicate that the energy production related to sharecropper condition increased $469 \%$ in this period and the energy production related to the tenant condition increased $112 \%$. In the case of energy production related to proprietary only had an increase of $16 \%$. Relationship into the increase of tenancy and sharecropping with the increase of production of raw sugarcane and the increase of renewable energy production using biomass residues of raw sugarcane in the sugarcane agroindustry in Brazil was found.

The authors acknowledge the financial support of the Project Concytec (Peru) - World Bank "Improvement and expansion of services of the national system of science, technology and technological innovation" 8682-PE, through its executing unit ProCiencia (Contract 010-2019-Fondecyt).

\section{References}

1. M. U. Lopes, Feasibility model for decisionmaking on land lease: case study in a sugarcane plant in the Triângulo Mineiro. São Paulo: Foundation Getúlio Vargas, School of Economics of São Paulo, Master's Thesis (2018).

2. M. D. M Oliveira, K. Nachiluk, Informações Econômicas, São Paulo, V. 41(1), 5 (2011)

3. E. Birru, C. Erlich, A. Martin, Biomass Conv. Bioref.. 9, 267 (2019). DOI:10.1007/s13399-0180349-z.

4. I.C.de Miranda, Energy use from biomass residues: bagasse and sugarcane straw. Rio de Janeiro: School of Chemistry, Federal University of Rio de Janeiro /UFRJ, Master's Thesis (2009).

5. A.C. Sant'Anna, G. Granco, J.S. Bergtold M.M. Caldas, T. Xia, P. Mais, T. Link, W. Lorenzani, $\mathrm{W} .$, The challenges of expanding sugarcane: the perception of producers and landowners in Goiás and Mato Grosso do Sul. In Quarenta Anos de Etanol em larga escala no Brasil: desafios, crise e perspectivas (Santos, G. R. Dos (org.). Brasília: Instituto de Pesquisa Econômica Aplicada - Ipea, Chapter 4, p. 113, 2016)

6. FAO, Voluntary guidelines on responsible land management, fishing and forests in the context of national food security. Rome (2012).

7. S. R. A. Ávila, Socioeconomic effects of the expansion of sugar cane in the São Patricio valley. 
University of Brasília, Brazil, Master's Thesis (2009).

8. S.N.R. Guedes, E. T. Terci, M.T.M. Peres, Lavras: Organizações Rurais \& Agroindustriais, 9 (2), 229 (2007).

9. Organization of Sugarcane Planters in the CentreSouth Region of Brazil (ORPLANA) (2019). Segmented Profile of the Sugarcane Producer 2018/2019. Research Report. On-line. Access in: January 27, 2021.

http://www.orplana.com.br/uploads/segmentacana2019.pdf

10. T.R.A. Ficarelli, H. Ribeiro, Informações Econômicas, São Paulo, 40 (1), 44 (2010).

11. L. A. C. Margarido, Land Leasing System in the Sugar-Alcohol Sector of the São Paulo State. Piracicaba: School of Agriculture "Luiz de Queiroz" /ESALQ, University of São Paulo/USP, Master's Thesis (1987).

12. A.C. dos S. Barbosa, M. A. F. de S. Nogueira, M. da S. Garcia, M. M. Schlindwein, The economic development of Mato Grosso do Sul against sugar cane leasing contracts. In: Anais do $57^{\circ}$ Congresso da SOBER. Universidade Estadual de Santa Cruz, Ilhéus (BA), 21 - 25 de July (2019).

13. P.J. de Almeida, A.M. Buainain, Land Use Policy, 52, 206 (2016).

14. D. A. L.L. Lima, J.R. Garcia, A.C.P. Vieira, J.M. F.J. da Silveira, Revista Espacios, 33 (11), 1 (2012). 